\title{
Tuberculosis: evidence review for newly arriving immigrants and refugees
}

\author{
Christina Greenaway MD MSc, Amelia Sandoe MPH, Bilkis Vissandjee PhD, lan Kitai MB BCh, \\ Doug Gruner MD, Wendy Wobeser MD MSc, Kevin Pottie MD, Erin Ueffing BHSc MHSc, Dick \\ Menzies MD MSc, Kevin Schwartzman MD MPH; for the Canadian Collaboration for Immigrant \\ and Refugee Health
}

\section{ABSTRACT}

Background: The foreign-born population bears a disproportionate health burden from tuberculosis, with a rate of active tuberculosis 20 times that of the non-Aboriginal Canadian-born population, and could therefore benefit from tuberculosis screening programs. We reviewed evidence to determine the burden of tuberculosis in immigrant populations, to assess the effectiveness of screening and treatment programs for latent tuberculosis infection, and to identify potential interventions to improve effectiveness.

Methods: We performed a systematic search for evidence of the burden of tuberculosis in immigrant populations and the benefits and harms, applicability, clinical considerations, and implementation issues of screening and treatment programs for latent tuberculosis infection in the general and immigrant populations. The quality of this evidence was assessed and ranked using the GRADE approach (Grading of Recommendations Assessment, Development and Evaluation).

Results: Chemoprophylaxis with isoniazid is highly efficacious in decreasing the development of active tuberculosis in people with latent tuberculosis infection who adhere to treatment. Monitoring for hepatotoxicity is required at all ages, but close monitoring is required in those 50 years of age and older. Adherence to screening and treatment for latent tuberculosis infection is poor, but it can be increased if care is delivered in a culturally sensitive manner.

Interpretation: Immigrant populations have high rates of active tuberculosis that could be decreased by screening for and treating latent tuberculosis infection. Several patient, provider and infrastructure barriers, poor diagnostic tests, and the long treatment course, however, limit effectiveness of current programs. Novel approaches that educate and engage patients, their communities and primary care practitioners might improve the effectiveness of these programs.

\section{The cases}

Ousman, a 32-year-old man; his 8-year-old daughter, Nene; and his 65-year-old mother, Mariama, from Casamance, Senegal, speak only Wolof and arrived in Canada six months ago from a refugee camp. What, if any, screening for latent tuberculosis should be done for this family?

\section{Key points}

- Foreign-born people account for $65 \%$ of all those with active tuberculosis in Canada, and subgroups have up to a 500-fold increased risk of active tuberculosis compared with the non-Aboriginal Canadian-born population.

- The Canadian Collaboration for Immigrant and Refugee Health recommends screening certain groups as soon as possible on arrival in Canada with a tuberculin skin test and treating for latent tuberculosis infection in those found to be positive, after ruling out active tuberculosis.

- Although isoniazid is highly efficacious in decreasing the development of active tuberculosis in those with latent tuberculosis infection, monitoring for hepatotoxicity is required for all ages; close monitoring is required for those over 50 years of age and those with pre-existing liver disease, alcoholism or concomitant use of hepatotoxic drugs.

- Adherence to screening and treatment for latent tuberculosis infection can be increased if delivered in a culturally sensitive manner.

Active pulmonary tuberculosis was recently diagnosed in Harjit, a 65-year-old man who immigrated to Canada from India at age 32. Diabetes was diagnosed when he was 40 years old, and chronic renal failure developed one year ago that required dialysis because of the diabetes. Should screening for latent tuberculosis have been done for this man, and if so when?

\section{Introduction}

Tuberculosis is an airborne transmissible disease that causes a substantial burden to patients, their contacts and society. Although tuberculosis is relatively uncommon in Canada

From the Division of Infectious Diseases and Clinical Epidemiology and Commu nity Services Unit (Greenaway, Sandoe), SMBD Jewish General Hospital, McGill University, Montréal, Que.; the Faculty of Nursing (Vissandjee), University of Montreal, Montréal, Que.; the Department of Paediatrics, Division of Infectious Diseases (Kitai), Hospital for Sick Children, University of Toronto, Toronto, Ont.; the Department of Family Medicine (Gruner), University of Ottawa, Ottawa, Ont.; the Department of Medicine, Division of Infectious Diseases (Wobeser) Queen's University, Kingston, Ont.; the Institute of Population Health (Pottie, Ueffing), University of Ottawa, Ottawa, Ont.; and the Montreal Chest Institute (Menzies, Schwartzman), McGill University, Montréal, Que.

CMAJ 2011. DOI:10.1503/cmaj.090302 


\section{Box 1: Recommendations for preventing tuberculosis from the Canadian Collaboration for Immigrant and Refugee Health}

\section{Children}

Screen children and adolescents $<20$ years of age from countries with a high incidence of tuberculosis (smear-positive pulmonary tuberculosis > 15 per 100000 population) as soon as possible after their arrival in Canada with a tuberculin skin test and recommend treatment for latent tuberculosis infection if results are positive, after ruling out active tuberculosis.

\section{Adults}

Screen all refugees between 20 and 50 years of age from countries with a high incidence of tuberculosis as soon as possible after their arrival in Canada with a tuberculin skin test. Screen all other adult immigrants who have risk factors that increase the risk of active tuberculosis with a tuberculin skin test and recommend treatment for latent tuberculosis infection if results are positive, after ruling out active tuberculosis.

\section{Basis of recommendations}

\section{Balance of benefits and harms*}

The decision about whom to screen and offer treatment for latent tuberculosis is based on the balance between the potential benefit of treatment (decreasing the lifetime risk of active tuberculosis, which is influenced by age, presence of underlying medical conditions and immigration category) versus the potential harm of hepatotoxicity (which increases with age) and the poor effectiveness of isoniazid in many settings because of suboptimal uptake of screening and treatment. For several groups, screening for latent tuberculosis should be routinely performed, and those with positive results should be offered treatment. These groups are children from countries with a high incidence of tuberculosis (number needed to treat [NNT] 20-26, number needed to harm [NNH] 134-268), adults with risk factors for active tuberculosis (NNT 3-20, NNH variable) and refugees $<50$ years of age (NNT 15-26, $\mathrm{NNH} 49$ ). Screening for latent tuberculosis and offering treatment could also be considered for adult refugees 50-65 years of age (NNT 20-51, NNH 9-18) and other adults without underlying medical conditions $<65$ years of age if adherence to treatment can be assured and hepatotoxicity carefully monitored to minimize harm. A decision to screen is a decision to offer treatment and to ensure adherence to treatment with appropriate counselling and monitoring.

\section{Quality of evidence}

High

\section{Values and preferences}

The guideline committee attributed more value to screening and treating latent tuberculosis infection to prevent active disease in patients and to prevent transmission of active disease and less value to the practitioner burden of screening and counselling.

*Estimated NNT and NNH are based on the following assumptions: seven years after arrival, the annual risk of active tuberculosis is $0.1 \%$; the relative risk of active tuberculosis is highest upon arrival and decreases with time (relative risk 5.1, compared with 1.4 seven years after arrival); the patient will live to age 80 years; the efficacy of isoniazid is $90 \%$; and adherence is $70 \%$.

programs for latent tuberculosis, to identify barriers or challenges to implementation of such programs and to highlight possible interventions to improve these programs. The recommendations for preventing tuberculosis from the Canadian Collaboration for Immigrant and Refugee Health are found in Box 1.

\section{Methods}

We used the 14-step approach developed by the methods team of the Canadian Collaboration for Immigrant and Refugee Health. ${ }^{4}$ The Clinician Summary Table highlights the population of interest, the epidemiology of disease within this population, population-specific considerations and potential key clinical actions (Appendix 1, available at www.cmaj.ca/cgi /content/full/cmaj.090302/DC1). We then constructed a logic model to define the clinical preventive actions (intervention), outcomes and key clinical questions. Details of the review are summarized in the tuberculosis technical document (www.ccirh.uottawa.ca).

\section{Search strategy for systematic reviews, guidelines and population- specific literature}

We designed a search strategy in consultation with a librarian to identify relevant systematic reviews and guidelines to address the burden of tuberculosis and the effectiveness of screening programs for tuberculosis (latent and active) in the immigrant population. For this search, we reviewed five electronic databases: MEDLINE (Ovid), MEDLINE InProcess, EMBASE, CINAHL and the Cochrane Database of Systematic

(1621 cases reported in 2006), it is costly (\$58 million in direct costs in Canada in 2004), treatment is lengthy, many patients require admission to hospital, and the mortality rate in patients with tuberculosis is still high (11\%). ${ }^{1,2}$

The foreign-born population bears a disproportionate burden of tuberculosis in Canada; $65 \%$ of all cases of active tuberculosis occur in foreign-born patients although they make up only $20 \%$ of the population. ${ }^{3}$ This is because most recent immigrants and refugees originate from countries with a high incidence of tuberculosis, and up to half harbour latent tuberculosis infection and are at risk of active tuberculosis. ${ }^{2}$ Successful control of tuberculosis in Canada will depend on decreasing rates of tuberculosis in the foreign-born population. We conducted a review to quantify the burden of tuberculosis in the migrant population, to identify those at highest risk of active tuberculosis, to describe the effectiveness of screening and treatment
Reviews from 1950 to Dec. 17, 2008. We conducted a similar search for the general population, with the same five databases and the same objectives but restricted the search dates to Jan. 1, 1996 to Dec. 17, 2008. We performed a separate search for tuberculosis among immigrants to address population-specific concerns including baseline risk or prevalence compared with the Canadian-born population; risk of clinically important outcomes; genetic and cultural factors (e.g., preferences, values, knowledge); and compliance variation using the same five databases (1950 to Dec. 17, 2008). An updating search, focusing on randomized controlled trials and systematic reviews during the period Jan. 1, 2007 to Jan. 1, 2010, was conducted to identify any recent publications that would change the position of the recommendation. We performed a Web-based search until September 2007 to identify guidelines on tuberculosis screening and treatment in the following websites: the 
Box 2: Grading of Recommendations Assessment, Development and Evaluation Working Group grades of evidence (www.gradeworkinggroup.org)

- High quality: Further research is very unlikely to change our confidence in the estimate of effect.

- Moderate quality: Further research is likely to have an important impact on our confidence in the estimate of effect and may change the estimate.

- Low quality: Further research is very likely to have an important impact on our confidence in the estimate of effect and is likely to change the estimate.

- Very low quality: We are very uncertain about the estimate.

CMA Infobase; the National Guideline Clearing House; the Canadian Task Force on Preventive Health Care; the Public Health Agency of Canada; the Canadian Lung Association; the US Preventive Task Force; Centers for Disease Control and Prevention; Infectious Disease Society of America; American Thoracic Society; National Institute for Health and Clinical Excellence; and the World Health Organization. We appraised eligible systematic reviews using the critical appraisal tool of the National Institute for Health and Clinical Evidence to assess systematic approach, transparency, quality of methods and relevance. We assessed relevant guidelines using the Appraisal of Guidelines for Research and Evaluation (AGREE) Instrument (www.agreecollaboration.org).

\section{Synthesis of evidence and values}

Evidence from systematic reviews, cohort studies and clinical trials using the summary of findings table from Grading of Recommendations Assessment, Development and Evaluation (GRADE) (Box 2), which assesses both relative and absolute effects of interventions (relative risk and absolute event rate), was synthesized. We appraised quality of data for each outcome using the GRADE quality assessment tool, which assesses study limitations, directness, precision, consistency and publication bias across all studies. In the search and synthesis of data on concerns specific to immigrants, clinically relevant considerations and implementation issues, as well as gaps in the research and evidence base, were identified.

\section{Results}

In the search for systematic reviews and guidelines for immigrants, 176 records were identified and screened, and 9 met the eligibility criteria. They included two guidelines from the United States that addressed screening for latent tuberculosis infection in immigrants, ${ }^{5,6}$ three articles that addressed tuberculosis screening issues in foreign-born patients, ${ }^{7-9}$ one review of postlanding surveillance in Canada, ${ }^{10}$ and three narrative reviews of screening immigrants and refugees that recommended screening for latent tuberculosis infection in immigrants and refugees, but none used a systematic review method. ${ }^{11-13}$

In the search for systematic reviews and guidelines for research involving the general population and tuberculosis, 3968 articles were identified, and 18 met the eligibility criteria. These reviews addressed diagnostic tests for latent tuberculosis infection, ${ }^{14,15}$ the effect of bacille Calmette-Guérin (BCG) on the tuberculin skin test, ${ }^{16-18}$ screening, ${ }^{7,19,20}$ factors that increase the risk of active tuberculosis, ${ }^{21-23}$ efficacy of treatment for latent tuberculosis infection ${ }^{24}$ and adherence to treatment, ${ }^{25}$ and included four US guidelines on controlling tuberculosis and treating latent tuberculosis infection. ${ }^{6,26-28}$ A flow chart of these combined searches is outlined in Figure 1. We identified the Canadian tuberculosis standards in the Web-based search. ${ }^{2}$ In the immigrant and tuberculosis search, 3073 primary articles were identified, of which 609 were relevant and addressed the

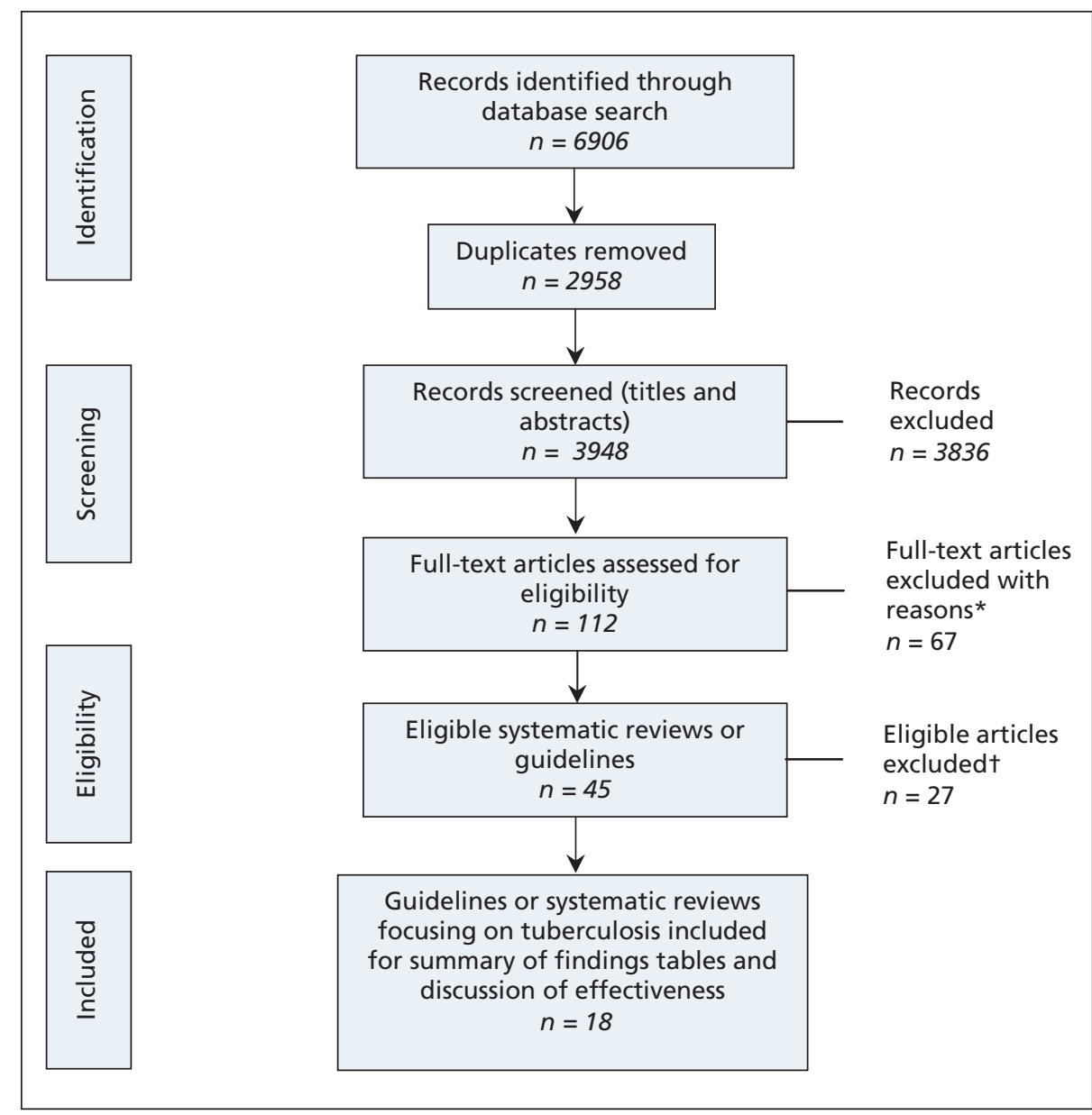

Figure 1: Literature search for systematic reviews and guidelines on tuberculosis. *Excluded because of lack of relevance. tExcluded because of lack of relevance, poor quality or outdated findings. 
following areas: epidemiology, diagnosis, screening, adherence and treatment for latent tuberculosis infection in immigrants.

\section{What is the burden of tuberculosis in immigrant populations?}

Tuberculosis is an important global health burden, with more than one billion people infected with latent tuberculosis result- ing in 9.2 million new active cases and 1.5 million deaths per year ( $>95 \%$ occur in low- to middle-income countries). ${ }^{29}$ Canada is a low-incidence country, with an overall rate of active tuberculosis of 5 cases/100 000 population. ${ }^{3,30,31}$ Most of these cases $(>65 \%)$ occur in foreign-born patients, who have an incidence of tuberculosis 20 times that in the non-Aboriginal Canadian-born population (16 v. 0.8 cases/100 000 population) but with rates as high as 500 times those in certain subgroups of immigrants (Table 1). ${ }^{8,32,33}$ In the past 40 years, most

Table 1: Incidence of tuberculosis/100 000 population for immigrants and refugees after arrival in high-income countries

Time since migration; incidence per 100000 population

\begin{tabular}{|c|c|c|c|c|}
\hline \multirow{2}{*}{ Country of origin } & \multirow[b]{2}{*}{ Overall rate } & \\
\hline & & $\leq 1 \mathrm{yr}$ & $>1-5 \mathrm{yr}$ & $\geq 5 \mathrm{yr}$ \\
\hline \multicolumn{5}{|l|}{ All world regions } \\
\hline All foreign-born $* \boldsymbol{\dagger}^{8,32,33}$ & 35 & 128 & 37 & 17 \\
\hline Refugees received by US $\ddagger^{37}$ & & 504 & & \\
\hline \multicolumn{5}{|l|}{ Latin America and Caribbean } \\
\hline All foreign-born $t^{8,32,33}$ & 17 & 76 & 26 & 10 \\
\hline Mexico $^{8}$ & 19 & 75 & 22 & 11 \\
\hline Haiti $^{8}$ & 55 & 428 & 98 & 28 \\
\hline Guatemala $^{8}$ & 32 & 173 & 58 & 12 \\
\hline Peru $^{8}$ & 47 & 233 & 90 & 23 \\
\hline \multicolumn{5}{|l|}{ Eastern Europe and Central Asia } \\
\hline All foreign-bornt $t^{8,32,33}$ & 17 & 65 & 19 & 13 \\
\hline Former Yugoslavia ${ }^{33}$ & 80 & 240 & 50 & 27 \\
\hline Refugees received by US ${ }^{37}$ & & 162 & & \\
\hline \multicolumn{5}{|l|}{ Middle East and North Africa } \\
\hline All foreign-born ${ }^{8,32}$ & 8 & 47 & 15 & 5 \\
\hline \multicolumn{5}{|l|}{ Sub-Saharan Africa } \\
\hline All foreign-born $t^{8,32,33}$ & 133 & 1120 & 120 & 48 \\
\hline Ethiopia $^{8}$ & 159 & 1515 & 189 & 59 \\
\hline Somalia ${ }^{33}$ & 710 & 1540 & 560 & 433 \\
\hline Refugees received by US ${ }^{37}$ & & 1107 & & \\
\hline \multicolumn{5}{|l|}{ South Asia } \\
\hline All foreign-born ${ }^{8}$ & 36 & 179 & 52 & 22 \\
\hline India ${ }^{8}$ & 40 & 150 & 51 & 21 \\
\hline Pakistan ${ }^{33}$ & 240 & 530 & 255 & 157 \\
\hline \multicolumn{5}{|l|}{ East Asia and Pacific } \\
\hline All foreign-bornt $t^{8,32,33}$ & 53 & 284 & 58 & 33 \\
\hline Philippines $^{8}$ & 52 & 543 & 66 & 30 \\
\hline Vietnam $^{8,33}$ & 87 & 602 & 112 & 51 \\
\hline China ${ }^{8,32}$ & 28 & 129 & 27 & 19 \\
\hline South Korea ${ }^{8}$ & 51 & 158 & 67 & 32 \\
\hline Refugees received by $\mathrm{US}^{37}$ & & 877 & & \\
\hline Low-incidence countries ${ }^{8,32}$ & 1.7 & 3.0 & 2.0 & 1.6 \\
\hline
\end{tabular}

*Total number of cases of tuberculosis in foreign-born immigrants and refugees $=11359$. $^{8,32,33}$

tOverall rate is a weighted average of all three studies ${ }^{8,32,33}$ and stratified rates are a weighted average of two studies. ${ }^{8,33}$

¥Total number of cases of tuberculosis in refugee population immigrated to the USA $=91$ and total refugee population $=18060 .^{37}$ 
new immigrants have originated from high-incidence countries (i.e., $>15$ cases of smear-positive pulmonary tuberculosis/100 000 population), 30\%-50\% of whom are infected with latent tuberculosis, resulting in a reservoir of approximately 1.5 million people in Canada with latent tuberculosis infection who are at risk of active tuberculosis. ${ }^{2}$

The prevalence of latent tuberculosis infection and the presence of factors associated with increased risk of active tuberculosis determine the people in whom active tuberculosis will develop. People with positive results of tuberculin skin tests who live in a low-incidence country and have no risk factors have an estimated annual probability of active tuberculosis developing of only $0.1 \%$ per year. This means that active disease will develop in only $5 \%-10 \%$ of those with latent tuberculosis infection. ${ }^{21}$ Recent transmission of tuberculosis confers an increased risk of active tuberculosis. This is extrapolated from studies in which 1\%-2\% of contacts have active tuberculosis immediately after diagnosis of the index cases. The highest risk of active tuberculosis occurs in the first year after exposure and decreases to the baseline risk ( $0.1 \%$ per year) 5 to 10 years after exposure. ${ }^{2,23}$

The strongest predictors for active tuberculosis in immigrant populations are global region of origin, immigration category, the presence of underlying medical comorbidity and the time since arrival.

\section{Region of origin}

Rates of tuberculosis are highest in immigrant populations that originate from world regions with the highest rates of tuberculosis, such as sub-Saharan Africa and Asia. Immigrants from these regions (rates of smear-positive pulmonary tuberculosis of 200-300/100 000 population) are more likely to be heavily exposed to tuberculosis, to have positive results of tuberculin skin tests and to have recently been exposed to tuberculosis..$^{29}$

\section{Immigration category}

The risk of active tuberculosis in refugee populations is about double that in immigrant populations (Table 1). ${ }^{34-37}$ This is likely due to both a higher prevalence of latent tuberculosis infection and having lived in crowded conditions that increase the likelihood of recent exposure to tuberculosis. ${ }^{38}$

\section{Presence of underlying comorbidity}

Underlying medical illnesses, especially any conditions that decrease local or systemic immunity, increase the rate of active tuberculosis to varying degrees, with HIV being the strongest risk factor. The issue of HIV screening in new immigrants and refugees is discussed in the HIV evidence review in this series.

\section{Time since arrival}

Rates of tuberculosis in immigrant and refugee populations, from all world regions, are highest within the first five years after arrival in a low-incidence region but decrease dramatically after the first year of arrival. Rates of active tuberculosis in the immigrant population, as compared with five years after arrival, are 5 to 10 times greater in the first year and two-fold greater one to four years after arrival (Table 1). . $^{8,32,33}$ This increase is most likely caused by the effect of recent exposure to tuberculosis before arrival. ${ }^{39}$ A practical Webbased tool can be used to help calculate the lifetime risk of active tuberculosis based on these factors (www.tstin $3 \mathrm{~d}$ .com/index.html $)^{40}$ (Tables 1 and 2). ${ }^{41-80}$

\section{Do screening and treatment for latent tuberculosis decrease morbidity from active tuberculosis?}

\section{Screening tests}

The tuberculin skin test and interferon gamma release assays (IGRAs) are available for diagnosing latent tuberculosis infection. The sensitivity of these tests is estimated to be $70 \%-$ $90 \%$, and the specificity for all tests is $>95 \%$ except for the tuberculin skin test in patients vaccinated with BCG $(60 \%)$

Table 2: Relative risk of developing active tuberculosis in the presence of underlying medical conditions

\begin{tabular}{|c|c|}
\hline Variable & Relative risk (RR) \\
\hline \multicolumn{2}{|l|}{ High risk $\left(\mathrm{RR}>\mathbf{6}^{*}\right)$} \\
\hline AIDS & $110-170^{41,42}$ \\
\hline HIV infection & $10-110^{43,44}$ \\
\hline $\begin{array}{l}\text { Transplantation (related to } \\
\text { immunosuppressant therapy) }\end{array}$ & $20-74^{45-48}$ \\
\hline Leukemia, lymphoma & $1.0-35^{49,50}$ \\
\hline Silicosis & $1.5-33^{51,52}$ \\
\hline $\begin{array}{l}\text { Chronic renal failure requiring } \\
\text { hemodialysis }\end{array}$ & $1.6-25^{53-56}$ \\
\hline Carcinoma of head and neck & $16^{57}$ \\
\hline Recent tuberculosis infection ( $\leq 2 \mathrm{yr}$ ) & $15^{58,59}$ \\
\hline $\begin{array}{l}\text { Abnormal results of chest radiography: } \\
\text { fibronodular disease }\end{array}$ & $6-19^{60-62}$ \\
\hline Tumour necrosis factor alpha inhibitors & $1.7-9^{63-66}$ \\
\hline \multicolumn{2}{|l|}{ Intermediate risk $(R R=3-6$ *) } \\
\hline Treatment with glucocorticoids & $4.9^{67}$ \\
\hline Diabetes mellitus (all types) & $2.0-4.1^{68-71}$ \\
\hline Young when infected (0-4 yr) & $2.2-5^{72}$ \\
\hline \multicolumn{2}{|l|}{ Low/intermediate risk $\left(\mathbf{R R}=1.3-3^{*}\right)$} \\
\hline $\begin{array}{l}\text { Underweight (<90\% ideal body weight; } \\
\text { for most people, a body mass index } \\
\leq 20)\end{array}$ & $1.6-3^{73-75}$ \\
\hline Cigarette smoker (1 pack per day) & $2-3^{76,77}$ \\
\hline $\begin{array}{l}\text { Abnormal results of chest radiography: } \\
\text { granuloma }\end{array}$ & $2^{61,78}$ \\
\hline Refugees & $2^{37,38,62,79}$ \\
\hline \multicolumn{2}{|l|}{ Low risk $(\mathrm{RR}=1 \mathrm{t})$} \\
\hline $\begin{array}{l}\text { Infected person, no known risk factor, } \\
\text { normal results of chest radiography } \\
\text { ("low-risk reactor") }\end{array}$ & $1^{80}$ \\
\hline
\end{tabular}

* Mean relative risk for each variable falls in this range. tIncidence of active tuberculosis developing, $0.1 \% / y$ r. 
owing to cross-reactivity. ${ }^{15}$ With tuberculin skin tests, the likelihood of a false-positive result caused by BCG decreases with time since vaccination, but it also depends on the age when the person was vaccinated. In the first 10 years after vaccination, up to $42 \%$ of patients vaccinated after age two will have positive results of tuberculin skin tests (even fewer of patients vaccinated as neonates), but data on the rate of decline conflict. ${ }^{17,81-84}$ In those receiving a tuberculin skin test more than 10 years after vaccination as a neonate, only $1 \%-2 \%$ of results will be positive, compared with $21 \%$ in those vaccinated after age two. Interpreting results of a tuberculin skin test is therefore particularly difficult in children less than 10 years of age. All HIV-positive patients should be screened for latent tuberculosis infection with a tuberculin skin test. ${ }^{2}$

Because there is no criterion standard for the diagnosis of latent tuberculosis infection, assessing and comparing the performance of these tests is challenging, especially when there are dis- crepancies. The major advantage of the tuberculin skin test over IGRAs is that the risk of active disease for different sizes of induration in tuberculin skin testing is well described, whereas very few prospective data exist for IGRAs. The most recent Canadian guidelines recommend using the tuberculin skin test as the primary screening tool for both adults and children and using IGRAs sequentially after tuberculin skin test in people with a high likelihood of a false-positive result from tuberculin skin test (i.e., low risk of tuberculosis infection). ${ }^{85}$ This recommendation is supported by a recent cost-effectiveness analysis. ${ }^{86}$ The major limitation of these tests is their inability to distinguish the $10 \%$ of people with latent tuberculosis infection in whom active tuberculosis will develop from the $90 \%$ in whom it will not.

Once a tuberculin skin test has been performed and the results found to be positive, all patients should undergo chest radiography to rule out active tuberculosis and be questioned for symptoms of active tuberculosis (chronic cough, weight loss, fever,

Table 3: Summary of findings table on isoniazid to prevent active tuberculosis

Patient or population: Varied: Smieja et al. $^{24}=$ populations at risk for developing active tuberculosis, with HIV-positive patients exluded; Bucher et al. ${ }^{87}=$ HIV-positive patients

Setting: Varied: Smieja et al. ${ }^{24}=$ US psychiatric institutions, veterans' hospitals in US, Eastern Europe, Alaska, Hong Kong, India, etc.; Bucher et al. ${ }^{87}=$ Mexico, Haiti, US, Zambia, Uganda and Kenya

Intervention: Isoniazid treatment to prevent active tuberculosis

Comparison: No treatment

Sources: Smieja MJ, Marchetti CA, Cook DJ, et al. Isoniazid for preventing tuberculosis in non-HIV infected persons [review]. Cochrane Database Syst Rev 1999;(1):CD001363. ${ }^{24}$

Bucher HC, Griffith LE, Guyatt GH, et al. Isoniazid prophylaxis for tuberculosis in HIV infection: a meta-analysis of randomized controlled trials. AIDS 1999;13:501-7.

\begin{tabular}{|c|c|c|c|c|c|c|}
\hline Outcomes, risk category & \multicolumn{2}{|c|}{ Absolute effect } & $\begin{array}{l}\text { Relative effect } \\
\qquad(95 \% \mathrm{Cl})\end{array}$ & $\begin{array}{l}\text { No. of } \\
\text { participants } \\
\text { (studies) }\end{array}$ & $\begin{array}{l}\text { GRADE quality } \\
\text { of evidence }\end{array}$ & $\begin{array}{l}\text { Comments } \\
(95 \% \mathrm{Cl})\end{array}$ \\
\hline \multicolumn{7}{|l|}{ Active tuberculosis } \\
\hline Intermediate risk* & $17 / 1000$ & $\begin{array}{l}10 \text { fewer per } \\
1000 \\
(12 \text { fewer to } \\
8 \text { fewer per } \\
1000)\end{array}$ & $\begin{array}{c}\text { RR } 0.40 \\
(0.31-0.52)\end{array}$ & 73375 (11) & Moderate $\ddagger \S$ & $\begin{array}{l}\text { NNT } 99 \\
(86-123)\end{array}$ \\
\hline $\begin{array}{l}\text { Highly compliant } \\
\text { (take }>80 \% \text { of } \\
\text { doses)* }\end{array}$ & $10 / 10000$ & $\begin{array}{l}7 \text { fewer per } \\
10000 \\
(8 \text { fewer to } \\
5 \text { fewer per } \\
10000)\end{array}$ & $\begin{array}{c}\text { RR } 0.20 \\
(0.13-0.31)\end{array}$ & $15696(1)$ & High & $\begin{array}{l}\text { NNT 85 } \\
\text { (78-98) }\end{array}$ \\
\hline $\begin{array}{l}\text { Hepatitis } \\
\text { (follow-up } 5 \mathrm{yr})^{* *}\end{array}$ & $1 / 1000$ & $\begin{array}{l}5 \text { more per } \\
1000 \\
(2 \text { more to } \\
11 \text { more per } \\
1000)\end{array}$ & $\begin{array}{l}\text { RR } 5.54 \\
(2.56-12)\end{array}$ & $20874(1)$ & Moderate & $\begin{array}{l}\text { NNH 220 } \\
(91-642)\end{array}$ \\
\hline \multicolumn{7}{|c|}{ 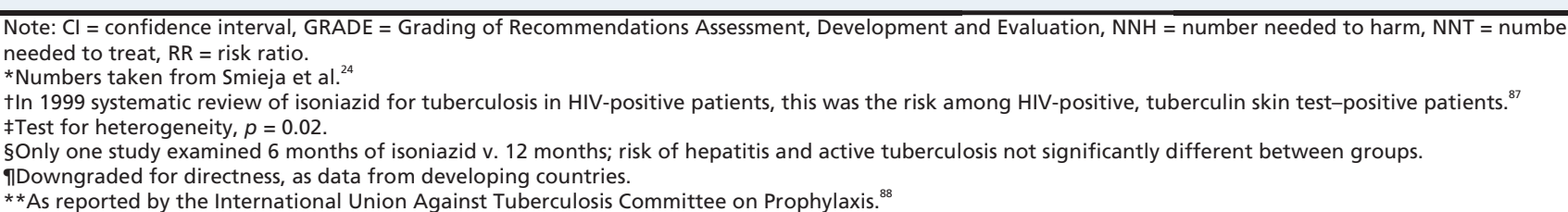 } \\
\hline
\end{tabular}


night sweats). If there is any suspicion of active tuberculosis, three samples of sputa or specimens from other sites (e.g., lymph node, cerebrospinal fluid) should be gathered for smear and culture before treatment for latent tuberculosis infection is started.

\section{Relative benefits and harms of treatment}

The efficacy of isoniazid compared with placebo in decreasing the likelihood of active tuberculosis developing in people with latent tuberculosis infection has been established in a Cochrane review (relative risk $0.40,95 \%$ confidence interval $0.31-0.52$ ) of 11 randomized controlled trials (Tables 3 and 4). ${ }^{24,87}$ The overall efficacy of isoniazid is $62 \%$ after 12 months of treatment but increases to $93 \%$ in those who adhere to treatment (i.e., take > $80 \%$ of their doses). ${ }^{88}$ Although a direct comparison of the efficacy of treatment for 9 versus 12 months has not been done, in a recent reanalysis, the maximal benefit of isoniazid was achieved at 9 months (Tables 5 and 6) ${ }^{89} \mathrm{~A}$ study on the effect of isoniazid resistance on efficacy of isoniazid chemoprophylaxis found that, at a mean prevalence of 7\%-10\% isoniazid resistance (the level in the immigrant population), isoniazid was the drug of choice and that only at very high rates $(>15 \%-20 \%)$ of isoniazid resistance were other regimens preferred. ${ }^{90.91}$

Hepatoxicity is a limitation of isoniazid therapy. It most commonly manifests as a transient asymptomatic increase in liver function $(10 \%-20 \%)$, rarely causes clinical hepatitis $(0.5 \%)$ - which resolves when treatment with isoniazid is stopped $^{92,94,95}$ - and very rarely causes fulminant hepatitis and liver failure $(<0.01 \%)$ leading to death or liver transplantation. ${ }^{28,96-98}$ Initial higher overall rates of hepatotoxicity (1\%) were reported among adults in the 1970s but were likely confounded by unrecognized underlying cirrhosis. ${ }^{99,100}$ Hepatoxicity among patients taking isoniazid is increased in those with pre-existing liver disease, alcoholism, concomitant use of hepatotoxic drugs and older age (Table 7). Although clinical and fulminant hepatitis are rare, they can occur at any age; this possibility underscores the importance of monthly monitoring for all patients and of teaching them to recognize symptoms of hepatitis (nausea, vomiting, abdominal pain, jaundice) and to stop medication as soon as worrisome symptoms occur. ${ }^{28,96}$ Adequate time must be taken, through interpreters if necessary, to ensure that all patients are appropriately informed and understand the risks and benefits of isoniazid, and they must be given a clear description of what to do if symptoms arise.

\section{Clinical considerations}

\section{How are immigrants screened for tuberculosis before and after arrival to Canada?}

All people applying for permanent residency, people claiming refugee status, and students and workers staying for more than six months are screened for active tuberculosis infection with chest radiography, followed by sputum culture if radiographic results are abnormal. Those found to have active tuberculosis must prove that they have been adequately treated and have negative results of culture before entry to Canada. Patients with previously treated tuberculosis or inactive tuberculosis (defined as those with latent tuberculosis infection and scarring visible on chest radiograph) are required to begin monitoring within 30 days after arrival in Canada in the Post-Landing Surveillance Program. ${ }^{2,10,20}$ There are no routine postlanding screening programs for latent tuberculosis infection for immigrants in Canada, but several programs exist (managed by different organizations) - for example, school-based screening, contact investigations, immigrant and refugee clinics, services for migrant workers and targeted screening of high-risk and undocumented migrants. ${ }^{106-123}$

Table 4: Summary of findings for using isoniazid among all age groups with latent tuberculosis infection

Patient or population: Patients with latent tuberculosis

Setting: Tuberculosis clinics in Memphis, Tennessee

Intervention: Isoniazid treatment to prevent active tuberculosis

Comparison: Younger people compared with older people

Source: Fountain FF, Tolley E, Chrsman CR, et al. Isoniazid hepatotoxicity associated with treatment of latent tuberculosis infection: a 7-year evaluation from a public health tuberculosis clinic. Chest 2005; 128:116-23. ${ }^{92}$

\begin{tabular}{|c|c|c|c|c|c|c|c|c|c|}
\hline \multirow[b]{3}{*}{ Outcome } & \multicolumn{3}{|c|}{ Absolute effect } & \multirow{2}{*}{\multicolumn{2}{|c|}{$\begin{array}{l}\text { Relative effect } \\
\quad(95 \% \mathrm{Cl})\end{array}$}} & \multirow{3}{*}{$\begin{array}{l}\text { No. of } \\
\text { participants } \\
\text { (studies) }\end{array}$} & \multirow{3}{*}{$\begin{array}{l}\text { GRADE } \\
\text { quality of } \\
\text { evidence }\end{array}$} & \multirow{2}{*}{\multicolumn{2}{|c|}{$\begin{array}{c}\text { Comments } \\
(95 \% \mathrm{Cl})\end{array}$}} \\
\hline & \multirow{2}{*}{$\begin{array}{c}\begin{array}{c}\text { Risk for } \\
\text { control } \\
\text { group }\end{array} \\
\text { Age 25-34 }\end{array}$} & \multicolumn{2}{|c|}{$\begin{array}{l}\text { Difference with older age } \\
\qquad(95 \% \mathrm{Cl})\end{array}$} & & & & & & \\
\hline & & Age $35-49$ & Age $\geq 50$ & $\begin{array}{l}\text { Age } \\
35-49\end{array}$ & $\begin{array}{l}\text { Age } \\
\geq 50\end{array}$ & & & $\begin{array}{l}\text { Age } \\
35-49\end{array}$ & $\begin{array}{l}\text { Age } \\
\geq 50\end{array}$ \\
\hline
\end{tabular}

Note: $\mathrm{Cl}=$ confidence interval, GRADE = Grading of Recommendations Assessment, Development and Evaluation, NNH $=$ number needed to harm,

RR = risk ratio.

*Fewer than 300 events. 


\section{Effectiveness of screening programs}

The preimmigration radiographic screening and the Post-Landing Surveillance Program have relatively little effect on controlling tuberculosis in Canada. Of all immigrants screened for tuberculosis before immigration, less than $1 \%$ are found to have active tuberculosis, and 3\%-5\% (8000-13 000 people/yr) are found to have inactive tuberculosis. ${ }^{2,9}$ Despite forming a high-risk group for active tuberculosis, they account for only a small proportion of all cases of tuberculosis in the foreign-born population (8\% in a study in Alberta), which could in part be due to program limitations. ${ }^{107,124-126}$

All the domestic screening programs (school-based, targeted immigrant or refugee, or contact tracing) for latent tuberculosis infection perform suboptimally; only about $47 \%$ (range $11 \%-72 \%$ ) of people with positive results of tuberculin skin tests actually complete treatment. ${ }^{106,123}$ This suboptimal performance is caused by losses and dropouts at the many different steps in the process, including failure to present for or complete screening, failure to report for medical evaluation if screening test is positive, physicians' failure to prescribe chemoprophylaxis for those eligible, patients' refusal to start treatment and failure to complete a course of isoniazid. ${ }^{7}$ Suboptimal screening is compounded by the fact that there is a large pool of foreign-born patients with latent tuberculosis infection $(30 \%-50 \%$ of all immigrants from countries in which tuberculosis is endemic) currently living in Canada or arriving in Canada each year. This pool includes not only one million people arriving annually from countries in which tuberculosis is endemic (visitors, students, temporary workers, etc.) but also the approximately four million people originating from countries in which tuberculosis is endemic who already live in Canada. ${ }^{127-129}$ Finally, exposure to tuberculosis caused by ongoing mobility of this population through travel to their countries of origin to visit family and friends could be substantial. ${ }^{130,131}$

\section{What should be considered when screening and treating?}

\section{Children}

Children less than 11 years of age do not undergo prearrival radiographic screening; for this and several other reasons, they could benefit greatly from screening for latent tuberculosis infection. There are many years of life in which active tuberculosis could develop in children, and children have a relatively low potential for hepatotoxicity (Table 7). ${ }^{99}$ If active tuberculosis develops, it is often difficult to diagnose because it is more often paucibacillary or extrapulmonary, and young children

Table 5: Estimated numbers needed to treat for latent tuberculosis infection to prevent one case of active tuberculosis by age, time since arrival and adherence

\begin{tabular}{|c|c|c|c|c|c|c|}
\hline Age (yr) & $\begin{array}{l}\text { Years lived in } \\
\text { Canada }\end{array}$ & $\begin{array}{l}\text { Cumulative } \\
\text { lifetime risk of } \\
\text { active } \\
\text { tuberculosis } \\
(\%)^{*} \dagger\end{array}$ & \multicolumn{4}{|c|}{ Number needed to treat } \\
\hline \multirow[t]{2}{*}{10} & 0 & 8.1 & 14 & 20 & 28 & 46 \\
\hline & 2 & 7.5 & 15 & 22 & 30 & 50 \\
\hline \multirow[t]{3}{*}{20} & 0 & 7.1 & 16 & 23 & 32 & 52 \\
\hline & 2 & 6.5 & 18 & 25 & 35 & 57 \\
\hline & 5 & 6.1 & 18 & 26 & 36 & 60 \\
\hline \multirow[t]{3}{*}{50} & 0 & 4.1 & 28 & 39 & 55 & 91 \\
\hline & 2 & 3.5 & 32 & 46 & 64 & 107 \\
\hline & 5 & 3.1 & 36 & 51 & 71 & 118 \\
\hline \multirow[t]{3}{*}{65} & 0 & 2.6 & 44 & 62 & 87 & 144 \\
\hline & 2 & 2.0 & 57 & 81 & 113 & 188 \\
\hline & 5 & 1.6 & 68 & 97 & 136 & 226 \\
\hline
\end{tabular}

*Assume $0.1 \%$ annual risk of infection with a relative risk of active tuberculosis developing for each year since arrival of $<1 \mathrm{yr} 5.08,1.1-2 \mathrm{yr} 2.96,2.1-3 \mathrm{yr} 2.35$,

$3.1-4$ yr 2.06, $4.1-5$ yr 1.87, 5.1-6 yr 1.89, 6.1-7 yr 1.36 all v. $>7$ yr. $^{21,32,92}$

tAssume subjects live to age $80 \mathrm{yr}$.

fFor $100 \%$ completion, assume $90 \%$ efficacy of isoniazid. ${ }^{24,88}$ 
Table 6: Estimated numbers needed to treat for latent tuberculosis infection to prevent one case of active tuberculosis in those with high and intermediate risk for development of active tuberculosis by age, time of arrival and adherence

\begin{tabular}{|c|c|c|c|c|c|c|c|}
\hline \multirow[b]{2}{*}{ Age (yr), level of risk } & \multirow{2}{*}{$\begin{array}{l}\text { Years lived in } \\
\text { Canada }\end{array}$} & \multirow{2}{*}{$\begin{array}{l}\text { Lifetime risk } \\
\text { of active } \\
\text { tuberculosis } \\
(\%)^{*} \dagger\end{array}$} & \multirow{2}{*}{$\begin{array}{l}\text { Lifetime risk of } \\
\text { active } \\
\text { tuberculosis with } \\
\text { risk factor }(\%) \ddagger\end{array}$} & \multicolumn{4}{|c|}{$\begin{array}{c}\text { Number needed to treat } \\
\text { Course of isoniazid completed§ }\end{array}$} \\
\hline & & & & $100 \% \rrbracket$ & $70 \%$ & $50 \%$ & $30 \%$ \\
\hline \multicolumn{8}{|l|}{35 yr } \\
\hline \multirow{2}{*}{$\begin{array}{l}\text { High } \\
\operatorname{RR}=10 * *\end{array}$} & 0 & 5.6 & 56 & 2 & 3 & 4 & 7 \\
\hline & 5 & 4.6 & 46 & 3 & 4 & 5 & 8 \\
\hline \multirow{3}{*}{$\begin{array}{l}\text { Intermediate } \\
R R=5^{\star \star}\end{array}$} & 0 & 5.6 & 28 & 4 & 6 & 8 & 14 \\
\hline & 2 & 5.0 & 25 & 5 & 7 & 9 & 15 \\
\hline & 5 & 4.6 & 23 & 5 & 7 & 10 & 16 \\
\hline $\begin{array}{l}\text { Low/intermediate } \\
R R=2^{\star *}\end{array}$ & 5 & 4.6 & 9 & 12 & 17 & 24 & 40 \\
\hline \multicolumn{8}{|l|}{$50 \mathrm{yr}$} \\
\hline \multirow{3}{*}{$\begin{array}{l}\text { High } \\
\operatorname{RR}=10 * *\end{array}$} & 0 & 4.1 & 41 & 3 & 4 & 6 & 10 \\
\hline & 2 & 3.5 & 35 & 4 & 5 & 7 & 11 \\
\hline & 5 & 3.1 & 31 & 4 & 6 & 8 & 12 \\
\hline \multirow{3}{*}{$\begin{array}{l}\text { Intermediate } \\
R R=5 * *\end{array}$} & 0 & 4.1 & 20 & 6 & 8 & 11 & 19 \\
\hline & 2 & 3.5 & 17 & 7 & 10 & 13 & 22 \\
\hline & 5 & 3.1 & 16 & 8 & 11 & 15 & 24 \\
\hline \multirow{2}{*}{$\begin{array}{l}\text { High } \\
\operatorname{RR}=10 * *\end{array}$} & 2 & 2.0 & 20 & 6 & 9 & 12 & 19 \\
\hline & 5 & 1.6 & 16 & 7 & 10 & 14 & 23 \\
\hline \multirow{3}{*}{$\begin{array}{l}\text { Intermediate } \\
\mathrm{RR}=5^{* *}\end{array}$} & 0 & 2.6 & 13 & 9 & 13 & 18 & 29 \\
\hline & 2 & 2.0 & 10 & 12 & 16 & 23 & 38 \\
\hline & 5 & 1.6 & 8 & 14 & 20 & 28 & 46 \\
\hline \multirow{3}{*}{$\begin{array}{l}\text { Low/intermediate } \\
R R=2^{\star *}\end{array}$} & 0 & 2.6 & 5 & 22 & 31 & 44 & 72 \\
\hline & 2 & 2.0 & 4 & 29 & 41 & 57 & 94 \\
\hline & 5 & 1.6 & 3 & 34 & 49 & 68 & 113 \\
\hline
\end{tabular}

Note: $\mathrm{RR}=$ relative risk

*Assume $0.1 \%$ annual risk of infection with a RR for active tuberculosis developing for each year since arrival of: < $1 \mathrm{yr} 5.08,1.1-2 \mathrm{yr} 2.96,2.1-3 \mathrm{yr} 2.35,3.1-4 \mathrm{yr}$ $2.06,4.1-5$ yr $1.87,5.1-6$ yr $1.89,6.1-7$ yr 1.36 all v. $>7$ yr. $^{21,32,92}$

tAssume subjects live to age $80 \mathrm{yr}$.

¥Multiply lifetime risk by relative risk.

$\S$ Proportion of patients prescribed isoniazid who completed a course of treatment.

IFFor $100 \%$ completion, assume $90 \%$ efficacy of isoniazid. ${ }^{24,8}$

**Midpoint of range. See Table 2 for range of RR for each category classified as high, intermediate, low/intermediate risk and associated conditions. 


\begin{tabular}{|c|c|c|}
\hline $\begin{array}{l}\text { Prevalence of } \\
\text { hepatoxicity (\%) }\end{array}$ & $\begin{array}{l}\text { Number needed } \\
\text { to harm }\end{array}$ & $\begin{array}{l}95 \% \text { confidence } \\
\text { interval }\end{array}$ \\
\hline 0.10 & 268 & 69-2513 \\
\hline 0.20 & 134 & 35-1256 \\
\hline 0.25 & 107 & 28-1005 \\
\hline 0.5 & 54 & $14-503$ \\
\hline 0.75 & 36 & 9-335 \\
\hline 1.0 & 27 & $7-251$ \\
\hline 1.25 & 21 & $6-201$ \\
\hline 1.50 & 18 & $5-168$ \\
\hline 1.75 & 15 & 4-144 \\
\hline 2.0 & 13 & $3-126$ \\
\hline 2.25 & 12 & $3-112$ \\
\hline 2.5 & 11 & 3-101 \\
\hline 2.75 & 10 & $3-91$ \\
\hline 3.0 & 9 & $2-84$ \\
\hline
\end{tabular}

Risk of hepatoxicity increases with age:

$<20$ yr $0.1 \%-0.2 \%^{97,98,101-105}$

$20-35$ yr $0.3 \%$

$35-49$ yr $0.5 \% \% 2,94,95$

$35-49$ yr $0.5 \%{ }^{92,20,95}$
$>50$ yr $1 \%-3 \%^{92,94,95}$

(especially those younger than five years of age) are more likely susceptible to severe or rapidly progressive disease. ${ }^{132,133}$

\section{Refugees}

Refugee populations have consistently had about a two-fold increased risk of active tuberculosis compared with the immigrant population, at least within the first year after arrival (Table 1). ${ }^{34-37}$ A higher prevalence of latent tuberculosis infection in the refugee population and having lived in crowded conditions that increase the likelihood of recent exposure to tuberculosis are contributing factors. ${ }^{38}$

\section{What are potential implementation issues?}

Barriers to uptake of screening and completion of treatment for latent tuberculosis infection include a combination of patient, provider and institutional factors. Patient barriers include the stigma of tuberculosis and its association with HIV, linguistic barriers and difficulties coming to appointments because of inconvenient clinic locations or limited clinic hours. ${ }^{121,134-136}$ Provider barriers to offering screening to migrants are related to inadequate knowledge of which migrants should be screened or how they should be followed up. ${ }^{137-139}$ Low adherence to treatment for latent tuberculosis infection is associated with barriers similar to those with screening latent tuberculosis. They include linguistic barriers, cultural taboos and stigmatization, low education level, perceived low risk of progressing from latent tuberculosis infection to active disease, belief that positive results from tuberculin skin tests are due to BCG, not wanting to have venipunctures, and economic factors (costs of travel, lack of insurance, delays in obtaining insurance, missed days at work). ${ }^{134,136,140-142}$
Increased adherence to tuberculin skin test screening has been seen with patient reminders (e.g., letters, phone calls), education of patients and physicians, and novel strategies, such as drive-by tuberculin skin test readings for taxi drivers. ${ }^{137,139,143}$ One study educating primary care providers on how and whom to screen for tuberculosis not only increased screening and identification of people with latent tuberculosis, but also increased identification of those with active tuberculosis. In this randomized clinical trial, screening was $0.4 \%$ and $57 \%$ in the nonintervention and intervention groups respectively, and identification of both those with latent tuberculosis infection (9\% to 19\%) and those with active tuberculosis (34\% v. $47 \%$ ) increased. ${ }^{137}$ Strategies that have increased adherence to treatment for latent tuberculosis infection in immigrant and refugee populations include patient reminders (calendar stickers for self-monitoring, phone calls, letters and directly observed therapy), adherence coaches who speak the same language as the patient, ongoing education of patients and providers, and cultural case management. ${ }^{25,144-146}$ Goldberg and colleagues found that when case managers were matched to the ethnic and linguistic background of patients and provided treatment for latent tuberculosis and monitoring during monthly home visits, adherence with treatment was substantially improved (82\% v. $37 \%$ ), as compared with standard clinic-based management before the intervention. ${ }^{146}$

\section{Other recommendations}

The Canadian Tuberculosis Committee, the Canadian Thoracic Society and the Canadian Paediatric Society recommend screening with a tuberculin skin test the following people from countries with high incidence of tuberculosis: children younger than 15 years living in Canada for less than two years, and people 15 years of age or older with factors that increase the risk of active tuberculosis or within two years after arrival if they have a known contact with tuberculosis (Table 2). 2.147 The US Centers for Disease Control and Prevention, the Infectious Disease Society of America and the American Thoracic Society recommend screening for latent tuberculosis infection with a tuberculin skin test or an IGRA for all immigrants and refugees who have arrived in the US within the previous five years, regardless of age, but with priority screening for refugees flagged for postlanding surveillance and children less than 15 years of age..$^{5,27,148}$

\section{The cases revisited}

Ousman and his daughter Nene should be screened for latent tuberculosis infection. Patients with positive results of tuberculin skin tests should be offered treatment if their risk of active tuberculosis outweighs the low risk of hepatotoxicity. Mariama should not be offered screening or treatment because, at her age, the risk of hepatotoxicity outweighs the benefit of treatment with isoniazid. Because the family speaks only Wolof, a translator must be used to ensure that family members understand the risks and benefits of isoniazid and know to stop treatment if symptoms of hepatitis arise. 
Harjit likely had latent tuberculosis infection upon arrival to Canada and at that time had an approximately $6 \%$ lifetime risk of active tuberculosis. When diabetes developed, the risk increased 2- to 4-fold, and chronic renal failure with dialysis increased the risk 15-fold. Educating patients and practitioners to recognize subgroups that would benefit from targeted screening and treatment for latent tuberculosis infection will be essential to avoid missed opportunities for prevention.

\section{Conclusions and research needs}

The magnitude of human migration from regions with high to low incidence of tuberculosis has reached an unprecedented level. Control of tuberculosis in low-incidence settings will require novel strategies to ensure increased uptake of screening and completion of treatment for latent tuberculosis in the foreign-born population. These strategies will need to consider the challenges of accessing all foreign-born groups at risk of latent tuberculosis infection. Investment in tuberculosis education programs for patients and providers and in infrastructure is needed, so that screening and treatment programs for latent tuberculosis can be offered in a culturally sensitive manner with good access to translators. Consideration should be given to developing tuberculosis prevention programs in the context of comprehensive and integrated preventive health care in primary care, where a long-term trusting relationship can be established. Key future needs include new diagnostic tests to identify the few patients with latent tuberculosis infection in whom active tuberculosis will develop, and to develop well-tolerated, short-course treatment regimens for latent tuberculosis. Ultimately, the long-term solution will be to invest in global tuberculosis control to decrease the burden of tuberculosis in migrants to Canada.

This article has been peer reviewed.

Competing interests: None declared.

Contributors: All authors contributed to conception and refinement of the study design and to analysis and interpretation of the data. Christina Greenaway drafted the initial manuscript, and all other authors provided critical revisions. All authors approved the final manuscript submitted for publication.

Acknowledgements: The authors thank Peter Tugwell, John Feightner and Vivian Welch for their invaluable methodologic support throughout this project.

Funding: Christina Greenaway and Dick Menzies receive salary support from the Fonds de la Recherche en Santé du Québec through the Chercheur Boursier Clinicien and Chercheur National programs, respectively. The Canadian Collaboration for Immigrant and Refugee Health Steering Committee acknowledges the funding support of the Chronic Disease Branch of the Public Health Agency of Canada and Canadian Institutes of Health Research (Institute of Health Services and Policy Research), the Champlain Local Health Integrated Network and the Calgary Refugee Program. The views expressed in this report are the views of the authors and do not necessarily reflect those of the funders.

\section{REFERENCES}

1. Menzies D, Oxlade O, Lewis M. Costs for tuberculosis care in Canada. Ottawa (ON): Public Health Agency of Canada; 2006

2. Canadian tuberculosis standards. 6th ed. Ottawa $(\mathrm{ON})$ : Tuberculosis Prevention and Control, Public Health Agency of Canada, Canadian Lung Association/Canadian Thoracic Society; 2007.

3. Public Health Agency of Canada. Tuberculosis in Canada 2006: pre-release. Ottawa (ON): The Agency; 2007.

4. Tugwell P, Pottie K, Welch V, et al. Evaluation of evidence-based literature and formation of recommendations for the Clinical Preventive Guidelines for Immigrants and Refugees in Canada. CMAJ 2010 June 23 [Epub ahead of print].

5. Controlling tuberculosis in the United States: recommendations from the American Thoracic Society, CDC, and the Infectious Diseases Society of America. MMWR Morb Mortal Wkly Rep 2005;54(RR-12):1-81

6. Recommendations for prevention and control of tuberculosis among foreign-born persons. Report of the Working Group on Tuberculosis Among Foreign-Born Persons. MMWR Morb Mortal Wkly Rep 1998;47(RR-16):1-29.

7. Dasgupta K, Menzies D. Cost-effectiveness of tuberculosis control strategies among immigrants and refugees. Eur Respir J 2005;25:1107-16.

8. Cain KP, Haley CA, Armstrong LR, et al. Tuberculosis among foreign-born persons in the United States: achieving tuberculosis elimination. Am J Respir Crit Care Med 2007; 175:75-9.

9. Thomas RE, Gushulak B. Screening and treatment of immigrants and refugees to Canada for tuberculosis: implications of the experience of Canada and other industrialized countries. Can J Infect Dis 1995;6:246-55.

10. Canadian guidelines for the investigation and follow-up of individuals under medical surveillance for tuberculosis after arrival in Canada. Can Commun Dis Rep 2001;27:157-65

11. Walker PF, Jaranson J. Refugee and immigrant health care. Med Clin North Am 1999;83:1103-20,viii.

12. Barnett E. Infectious disease screening for refugees resettled in the United States. Clin Infect Dis 2004;39:833-41.

13. Stauffer WM, Kamat D, Walker PF. Screening of international immigrants, refugees, and adoptees. Prim Care 2002;29:879-905.

14. Menzies D, Pai M, Comstock G. Meta-analysis: new tests for the diagnosis of latent tuberculosis infection: areas of uncertainty and recommendations for research. Ann Intern Med 2007;146:340-54.

15. Pai M, Zwerling A, Menzies D. Systematic review: T-cell-based assays for the diagnosis of latent tuberculosis infection: an update. Ann Intern Med 2008;149:177-84.

16. Wang L, Turner M, Elwood R, et al. A meta-analysis of the effect of Bacille Calmette Guérin vaccination on tuberculin skin test measurements. Thorax 2002; 57:804-9.

17. Farhat M, Greenaway C, Pai M, et al. False-positive tuberculin skin tests: what is the absolute effect of BCG and non-tuberculous mycobacteria? Int J Tuberc Lung Dis 2006;10:1192-204.

18. Joos TJ, Miller WC, Murdoch DM. Tuberculin reactivity in bacille CalmetteGuerin vaccinated populations: a compilation of international data. Int J Tuberc Lung Dis 2006;10:883-91.

19. Tan L, Altman R, Nielsen N; Council on Scientific Affairs AMA. Screening nonimmigrant visitors to the United States for tuberculosis: report of the Council on Scientific Affairs. Arch Intern Med 2001;161:334-40.

20. Heywood N, Kawa B, Long R, et al. Guidelines for the investigation and follow-up of individuals under medical surveillance for tuberculosis after arriving in Canada: a summary. CMAJ 2003;168:1563-5

21. Watkins RE, Brennan R, Plant AJ. Tuberculin reactivity and the risk of tuberculosis: a review. Int J Tuberc Lung Dis 2000;4:895-903.

22. Jeon CY, Murray MB. Diabetes mellitus increases the risk of active tuberculosis: a systematic review of 13 observational studies. PLoS Med 2008;5:e152.

23. Morrison J, Pai M, Hopewell PC. Tuberculosis and latent tuberculosis infection in close contacts of people with pumonary tuberculosis in low-income and middleincome countries: a systematic review and meta-analysis. Lancet Infect Dis 2008;8:359-68.

24. Smieja MJ, Marchetti CA, Cook DJ, et al. Isoniazid for preventing tuberculosis in non-HIV infected persons [review]. Cochrane Database Syst Rev 1999(1):CD001363.

25. Hirsch-Moverman Y, Daftary A, Franks J, et al. Adherence to treatment for latent tuberculosis infection: systematic review of studies in the US and Canada. Int J Tuberc Lung Dis 2008;12:1235-54.

26. American Thoracic Society, Centers for Disease Control and Prevention/Infectious Diseases Society of America. Controlling tuberculosis in the United States. Am J Respir Crit Care Med 2005;172:1169-227.

27. American Thoracic Society. Targeted tuberculin testing and treatment of tuberculosis infection. Am J Respir Crit Care Med 2000;161:S221-47.

28. Pediatric Tuberculosis Collaborative Group. Targeted tuberculin skin testing and treatment of latent tuberculosis infection in children and adolescents. Pediatrics 2004; 114:1175-201

29. World Health Organization. WHO Report 2008. Global tuberculosis control. Surveillance, planning, financing. Geneva (Switzerland): The Organization; 2008.

30. Public Health Agency of Canada. Tuberculosis in Canada 2004. Ottawa (ON): The Agency; 2007

31. Tuberculosis and respiratory diseases. Tuberculosis in Canada 2000. Ottawa (ON): Health Canada; 2003

32. Creatore MI, Lam M, Wobeser WL. Patterns of tuberculosis risk over time among recent immigrants to Ontario, Canada. Int J Tuberc Lung Dis 2005;9:667-72.

33. Farah MG, Meyer HE, Selmer R, et al. Long-term risk of tuberculosis among immigrants in Norway. Int J Epidemiol 2005;34:1005-11.

34. Tuberculosis among Indochinese refugees-an update. MMWR Morb Mortal Wkly Rep 1981;30:603-6.

35. Enarson DA. Active tuberculosis in Indochinese refugees in British Columbia. CMAJ 1984;131:39-42.

36. Wilcke JT, Poulsen S, Askgaard DS, et al. Tuberculosis in a cohort of Vietnamese refugees after arrival in Denmark 1979-1982. Int J Tuberc Lung Dis 1998;2:219-24.

37. Thorpe LE, Laserson K, Cookson S, et al. Infectious tuberculosis among newly 
arrived refugees in the United States. N Engl J Med 2004;350:2105-6.

38. Marras TK, Wilson J, Wang EEL, et al. Tuberculosis among Tibetan refugee claimants in Toronto: 1998 to 2000. Chest 2003;124:915-21.

39. Hadzibegovic DS, Maloney SA, Cookson ST, et al. Determining TB rates and TB case burden for refugees. Int J Tuberc Lung Dis 2005;9:409-14.

40. Menzies D, Gardiner G, Farhat M, et al. Thinking in three dimensions: a webbased algorithm to aid the interpretation of tuberculin skin test results. Int J Tuberc Lung Dis 2008;12:498-505.

41. Guelar A, Gatell J, Verdejo J, et al. A prospective study of the risk of tuberculosis among HIV-infected patients. AIDS 1993;7:1345-9.

42. Antonucci G, Girardi E, Raviglione M, et al. Risk factors for tuberculosis in HIV infected persons. A prospective cohort study. The Gruppo Italiano di Studio Tubercolosi e AIDS (GISTA). JAMA 1995;274:143-8.

43. Selwyn PA, Hartel D, Lewis VA. A prospective study of the risk of tuberculosis among intravenous drug users with human immunodeficiency virus infection. $N$ Engl J Med 1989;320:545-50.

44. Wood R, Maartens G, Lombard C. Risk factors for developing tuberculosis in HIV-1-infected adults from communities with low or very high incidence of tuberculosis. J Acquir Immune Defic Syndr 2000;23:75-80.

45. Sakhuja V, Jha V, Varma $\mathrm{P}$, et al. The high incidence of tuberculosis among renal transplant recipients in India. Transplantation 1996;61:211-5.

46. Aguado JM, Herrero JA, Gavalda J, et al. Clinical presentation and outcome of tuberculosis in kidney, liver, and heart transplant recipients in Spain. Transplantation 1997;63:1278-86.

47. Meyers BR, Halpern M, Sheiner P, et al. Tuberculosis in liver transplant patients. Transplantation 1994;58:301-6.

48. Miller RA, Lanza LA, Kline JN, et al. Mycobacterium tuberculosis in lung transplant recipients. Am J Respir Crit Care Med 1995;152:374-6.

49. Ruiz-Argüelles GJ, Mercado-DÍaz MA, Ponce-De-León S, et al. Studies on lymphomata, III: lymphomata, granulomata and tuberculosis. Cancer 1983;52:258-62.

50. Morrow LB, Anderson RE. Active tuberculosis in leukemia: malignant lymphoma and myelofibrosis. Arch Pathol 1965;79:484-93.

51. Cowie RL. The epidemiology of tuberculosis in gold miners with silicosis. Am J Respir Crit Care Med 1994;150:1460-2.

52. Hong Kong Chest Service/Tuberculosis Research Centre MBMRC. A double-blind placebo-controlled clinical trial of three antituberculosis chemoprophylaxis regimens in patients with silicosis in Hong Kong. Am Rev Respir Dis 1992;145:36-41.

53. Malhotra KK, Parashar MK, Sharma RK, et al. Tuberculosis in maintenance haemodialysis patients. Study from an endemic area. Postgrad Med J 1981;57:492-8.

54. Lundin AP, Adler AJ, Berlyne GM, et al. Tuberculosis in patients undergoing maintenance hemodialysis. Am J Med 1979;67:597-602.

55. Andrew OT, Schoenfeld PY, Hopewell PC, et al. Tuberculosis in patients with end-stage renal disease. Am J Med 1980;68:59-65.

56. Pradhan RP, Katz LA, Nidus BD, et al. Tuberculosis in dialyzed patients. JAMA 1974;229:798-800.

57. Rieder HL, Cauthen GM, Comstock GW, et al. Epidemiology of tuberculosis in the United States. Epidemiol Rev 1989;11:79-98.

58. Sutherland I. The evolution of clinical tuberculosis in adolescents. Tubercle 1966; 47:308.

59. Sutherland I. Recent studies in the epidemiology of tuberculosis, based on the risk of being infected with tubercle bacilli. Adv Tuberc Res 1976;19:1-63.

60. Grzybowksi S, McKinnon NE, Tuters L, et al. Reactivations in inactive pulmonary tuberculosis. Am Rev Respir Dis 1966;93:352-60.

61. Grzybowski S, Fishaut H, Rowe J, et al. Tuberculosis among patients with various radiologic abnormalities, followed by the chest clinic service. Am Rev Respir Dis 1971;104:605-8.

62. Nolan CM, Elarth AM. Tuberculosis in a cohort of Southeast Asian refugees. A five-year surveillance study. Am Rev Respir Dis 1988;137:805-9.

63. Keane J, Gershon S, Wise R, et al. Tuberculosis associated with infliximab, a tumor necrosis factor alpha-neutralizing agent. N Engl J Med 2001;345:1098-104.

64. Brassard P, Kezouh A, Suissa S. Antirheumatic drugs and the risk of tuberculosis. Clin Infect Dis 2006;43:717-22.

65. Carmona L, Gómez-Reino J, Rodríguez-Valverde V, et al. Effectiveness of recommendations to prevent reactivation of latent tuberculosis infection in patients treated with tumor necrosis factor antagonists. Arthritis Rheum 2005;52:1766-72.

66. Wolfe F, Michaud K, Anderson J, et al. Tuberculosis infection in patients with rheumatoid arthritis and the effect of infliximab therapy. Arthritis Rheum 2004;50:372-9

67. Jick SS, Lieberman ES, Rahman MU, et al. Glucocorticoid use, other associated factors, and the risk of tuberculosis. Arthritis Rheum 2006;55:19-26.

68. Pablos-Mendez A, Blustein J, Knirsch CA. The role of diabetes mellitus in the higher prevalence of tuberculosis among Hispanics. Am J Public Health 1997;87: 574-9.

69. Kim SJ, Hong YP, Lew WJ, et al. Incidence of pulmonary tuberculosis among diabetics. Tuber Lung Dis 1995;76:529-33.

70. Boucot KR. Diabetes mellitus and pulmonary tuberculosis. J Chronic Dis 1957;6: 256-79.

71. Silwer H, Oscarsson PN. Incidence and coincidence of diabetes mellitus and pulmonary tuberculosis in a Swedish county. Acta Med Scand 1958:335:1-48.

72. Comstock GW, Livesay VT, Woolpert SF. The prognosis of a positive tuberculin reaction in childhood and adolescence. Am J Epidemiol 1974;99:131-8

73. Comstock GW. Frost revisited: the modern epidemiology of tuberculosis. Am J Epidemiol 1975; 102:363-82

74. Palmer CE, Jablon S, Edwards PQ. Tuberculosis morbidity of young men in rela- tion to tuberculin sensitivity and body build. Am Rev Tuberc 1957;76:517-39.

75. Edwards LB, Livesay VT, Acquaviva FA, et al. Height, weight, tuberculous infection, and tuberculous disease. Arch Environ Health 1971;22:106-12.

76. Maurya V, Vijayan V, Shah A. Smoking and tuberculosis: an association overlooked. Int J Tuberc Lung Dis 2002;6:942-51.

77. Bates MN, Khalakdina A, Pai M, et al. Risk of tuberculosis from exposure to tobacco smoke: a systematic review and meta-analysis. Arch Intern Med 2007;167:335-42.

78. Horwitz O, Wilbek E, Erickson P. Epidemiological basis of tuberculosis eradication. 10. Longitudinal studies on the risk of tuberculosis in the general population of a low-prevalence area. Bull World Health Organ 1969;41:95-113.

79. Truong DH, Hedemark LL, Mickman JK, et al. Tuberculosis among Tibetan immigrants from India and Nepal in Minnesota, 1992-1995. JAMA 1997;277:735-8.

80. Comstock GW, Edwards LB, Livesay VT. Tuberculosis morbidity in the US Navy: its distribution and decline. Am Rev Respir Dis 1974;110:572-80.

81. Marcus JH, Khassis Y. Tuberculin sensitivity in BCG vaccinated infants and children in Israel. Acta Tuberc Pneumol Scand 1965;46:113-22.

82. Karalliede S, Katugha LP, Uragoda CG. Tuberculin response of Sri Lankan children after BCG vaccination at birth. Tubercle 1987;68:33-8.

83. Reid JK, Ward H, Marciniuk D, et al. The effect of neonatal BCG vaccination on PPD testing on Canadian Aboriginal children. Chest 2007;131:1806-10.

84. Sepulveda RL, Ferrer X, Latrach C, et al. The influence of Calmette-Guérin bacillus immunization on the booster effect of tuberculin testing in healthy young adults. Am Rev Respir Dis 1990;142:24-8.

85. Updated recommendations on interferon gamma release assays for latent tuberculosis infection. An Advisory Committee Statement (ACS). Can Commun Dis Rep 2008;34:1-13

86. Oxlade O, Schwartzman K, Menzies D. Interferon-gamma release assays and TB screening in high-income countries: a cost-effectiveness analysis. Int J Tuberc Lung Dis 2007;11:16-26.

87. Bucher HC, Griffith LE, Guyatt GH, et al. Isoniazid prophylaxis for tuberculosis in HIV infection: a meta-analysis of randomized controlled trials. AIDS 1999;13(4): $501-7$.

88. International Union Against Tuberculosis Committee on Prophylaxis. Efficacy of various durations of isoniazid preventive therapy for tuberculosis: five years of follow-up in the IUAT trial. Bull World Health Organ 1982;60:555-64.

89. Comstock GW. How much isoniazid is needed for prevention of tuberculosis among immunocompetent adults? Int J Tuberc Lung Dis 1999;3:847-50.

90. Public Health Agency of Canada. Tuberculosis drug resistance in Canada 2007 Ottawa (ON): The Agency; 2007.

91. Khan K, Muennig P, Behta M, et al. Global drug-resistance patterns and the management of latent tuberculosis infection in immigrants to the United States. $N$ Engl J Med 2002;347:1850-9.

92. Fountain FF, Tolley E, Chrsman CR, et al. Isoniazid hepatotoxicity associated with treatment of latent tuberculosis infection: a 7-year evaluation from a public health tuberculosis clinic. Chest 2005;128:116-23.

93. Horsburgh CR Jr. Priorities for the treatment of latent tuberculosis infection in the United States. N Engl J Med 2004;350:2060-7.

94. Nolan CM, Goldberg SV, Buskin SE. Hepatotoxicity associated with isoniazid preventive therapy: a 7-year survey from a public health tuberculosis clinic. JAMA 1999;281:1014-8.

95. LoBue PA, Moser KS. Use of isoniazid for latent tuberculosis infection in a public health clinic. Am J Respir Crit Care Med 2003;168:443-7.

96. Saukkonen J, Cohn D, Jasmer R, et al. An official ATS statement: hepatotoxicity of antituberculosis therapy. Am J Respir Crit Care Med 2006;174:935-52.

97. Wu SS, Chao CS, Vargas JH, et al. Isoniazid-related hepatic failure in children: a survey of liver transplantation centers. Transplantation 2007;84:173-9.

98. Palusci VJ, Ohare D, Lawrence RM. Hepatotoxicity and transaminase measurement during isoniazid chemoprophylaxis in children. Pediatr Infect Dis J 1995;14 144-8.

99. Kopanoff DE, Snider DE Jr, Caras GJ. Isoniazid-related hepatitis: a U.S. Public Health Service cooperative surveillance study. Am Rev Respir Dis 1978;117:991-1001.

100. Comstock GW. Prevention of tuberculosis among tuberculin reactors: maximizing benefits, minimizing risks. JAMA 1986;256:2729-30.

101. Nakajo MM, Rao M, Steiner P. Incidence of hepatotoxicity in children receiving isoniazid chemoprophylaxis. Pediatr Infect Dis J 1989;8:649-50.

102. Spyridis P, Sinaniotis C, Papadea I, et al. Isoniazid liver injury during chemoprophylaxis in children. Arch Dis Child 1979;54:65-7.

103. Litt IF, Cohen MI, McNamara H. Isoniazid hepatitis in adolescents. J Pediat 1976;89:133-5.

104. Beaudry PH, Brickman HF, Wise MB, et al. Liver enzyme disturbances during isoniazid chemoprophylaxis in children. Am Rev Respir Dis 1974;110:581-4.

105. Hsu KH. Isoniazid in the prevention and treatment of tuberculosis. A 20-year study of the effectiveness in children. JAMA 1974;229:528-33.

106. Richards B, Kozak R, Brassard P, et al. Tuberculosis surveillance among new immigrants in Montreal. Int J Tuberc Lung Dis 2005;9:858-64.

107. Dasgupta K, Schwartzman K, Marchand R, et al. Comparison of cost-effectivens of tuberculosis screening of close contacts and foreign-born populations. Am J Respir Crit Care Med 2000;162:2079-86.

108. Wells CD, Zuber PL, Nolan CM, et al. Tuberculosis prevention among foreign-born persons in Seattle-King County, Washington. Am J Respir Crit Care Med 1997;156: 573-7.

109. Saraiya M, Cookson S, Tribble $\mathrm{P}$, et al. Tuberculosis screening among foreignborn persons applying for permanent US residence. Am J Public Health 2002;92. $826-9$. 
110. Blum RN, Polish LB, Tapy JM, et al. Results of screening for tuberculosis in foreign-born persons applying for adjustment of immigration status. Chest 1993;103: 1670-4.

111. Brassard P, Steensma C, Cadieux L, et al. Evaluation of a school-based tuberculosis-screening program and associate investigation targeting recently immigrated children in a low-burden country. Pediatrics 2006;117:e148-56.

112. Yuan L, Richardson E, Kendall P. Evaluation of a tuberculosis screening program for high-risk students in Toronto schools. CMAJ 1995;153:925-32.

113. Sipan C, Blumberg E, Hovell M, et al. Screening Latino adolescents for latent tuberculosis infection (LTBI). Public Health Rep 2003;118:425-33.

114. Gounder CR, Driver CR, Scholten JN, et al. Tuberculin testing and risk of tuberculosis infection among New York City schoolchildren. Pediatrics 2003:111:e309-15.

115. Chang S, Wheeler L, Farrell K. Public health impact of targeted tuberculosis screening in public schools. Am J Public Health 2002;92:1942-5.

116. Adhikari N, Menzies R. Community-based tuberculin screening in Montreal: a cost-outcome description. Am J Public Health 1995;85:786-90.

117. D'Lugoff MI, Jones W, Kub J, et al. Tuberculosis screening in an at-risk immigrant Hispanic population in Baltimore city: an academic health center/local health department partnership. J Cult Divers 2002;9:79-85.

118. El-Hamad I, Casalini C, Matteelli A, et al. Screening for tuberculosis and latent tuberculosis infection among undocumented immigrants at an unspecialised health service unit. Int J Tuberc Lung Dis 2001;5:712-6.

119. Jereb J, Etkind S, Joglar O, et al. Tuberculosis contact investigations: outcomes in selected areas of the United States, 1999. Int J Tuberc Lung Dis 2003;7(Suppl 3): S384-90.

120. Poss JE. Factors associated with participation by Mexican migrant farmworkers in a tuberculosis screening program. Nurs Res 2000;49:20-8.

121. Carvalho AC, Saleri N, El-Hamad I, et al. Completion of screening for latent tuberculosis infection among immigrants. Epidemiol Infect 2005;133:179-85.

122. Doering D, Kocuipchyk R, Lester S. A tuberculosis screening and chemoprophylaxis project in children from a high risk population in Edmonton, Alberta. Can $J$ Public Health 1999;90:152-5.

123. Levesque JF, Dongier P, Brassard P, et al. Acceptance of screening and completion of treatment for latent tuberculosis infection among refugee claimants in Canada. Int J Tuberc Lung Dis 2004:8:711-7.

124. Long R, Sutherland K, Kunimoto D, et al. The epidemiology of tuberculosis among foreign-born persons in Alberta, Canada, 1989-1998: identification of high risk groups. Int J Tuberc Lung Dis 2002;6:615-21.

125. Uppaluri A, Naus M, Heywood N, et al. Effectiveness of the immigration medica surveillance program for tuberculosis in Ontario. Can J Infect Dis 2002;93:88-91.

126. Orr PH, Manfreda J, Hershfield ES. Tuberculosis surveillance in immigrants to Manitoba. CMAJ 1990;142:453-8.

127. Wobeser WL, Yuan L, Naus M, et al. Expanding the epidemiologic profile: risk fac tors for active tuberculosis in people immigrating to Ontario. CMAJ 2000;163:823-8.

128. Enarson D, Ashley M, Grzybowski S. Tuberculosis in immigrants to Canada. A study of present-day patterns in relation to immigration trends and birthplace. $A m$ Rev Respir Dis 1979;119:11-8.

129. Lobato MN, Hopewell PC. Mycobacterium tuberculosis infection after travel to or contact with visitors from countries with a high prevalence of tuberculosis. Am J Respir Crit Care Med 1998;158:1871-5.

130. Statistics Canada, Culture, Tourism and the Centre for Education Statistics, International Travel Section. International Travel 2006:1-86.

131. Cobelens FG, vanDeutekom H, Draayer-Jansen IW, et al. Risk of infection with Mycobacterium tuberculosis in travellers to areas of high tuberculosis endemicity. Lancet 2000;356:461-5.

132. Loeffler AM. Pediatric tuberculosis. Semin Respir Infect 2003;18:272-91.

133. Mandalakas AM, Starke JR. Current concepts of childhood tuberculosis. Semin Pediatr Infect Dis 2005;16:93-104.

134. Wyss LL, Alderman MK. Using theory to interpret beliefs in migrants diagnosed with latent TB. Online J Issues Nurs 2006;12:7.

135. Brewin P, Jones A, Kelly M, et al. Is screening for tuberculosis acceptable to immigrants? A qualitative study. J Public Health (Oxf) 2006;28:253-60.

136. Coreil J, Lauzardo M, Heurtelou M. Cultural feasibility assessment of tuberculosis prevention among persons of Haitian origin in South Florida. J Immigr Health 2004; 6:63-9.

137. Griffiths C, Sturdy P, Brewin P, et al. Educational outreach to promote screening for tuberculosis in primary care: a cluster randomised controlled trial. Lancet 2007 ; 369:1528-34.

138. LoBue PA, Moser K, Catanzaro A. Management of tuberculosis in San Diego County: a survey of physicians' knowledge, attitudes and practices. Int J Tuberc Lung Dis 2001;5:933-8.

139. Gany FM, Trinh-Shevrin C, Changrani J. Drive-by readings: a creative strategy for tuberculosis control among immigrants. Am J Public Health 2005;95:117-9.

140. Ailinger RL, Dear MR. Adherence to tuberculosis preventive therapy among Latino immigrants. Public Health Nurs 1998;15:19-24.

141. Pang SC, Harrison RH, Brearley J, et al. Preventive therapy for tuberculosis in Western Australia. Int J Tuberc Lung Dis 1998;2:984-8.

142. Shieh FK, Snyder G, Horsburgh CR, et al. Predicting non-completion of treatment for latent tuberculous infection: a prospective survey. Am J Respir Crit Care Med 2006; 174:717-21.

143. Catlos EK, Cantwell MF, Bhatia G, et al. Public health interventions to encourage TB Class A/B1/B2 Immigrants to present for TB screening. Am J Respir Crit Care Med 1998;158:1037-41.

144. Cass AD, Talavera GA, Gresham LS, et al. Structured behavioral intervention to increase children's adherence to treatment for latent tuberculosis infection. Int J Tuberc Lung Dis 2005;9:415-20.

145. Hovell MF, Sipan CL, Blumberg EJ, et al. Increasing Latino adolescents' adherence to treatment for latent tuberculosis infection: a controlled trial. Am J Public Health 2003; 93:1871-7.

146. Goldberg SV, Wallace J, Jackson JC, et al. Cultural case management of latent tuberculosis infection. Int J Tuberc Lung Dis 2004;8:76-82.

147. Wobeser W, Yuan L, Gushulak B, et al. Surveillance and screening in tuberculosis control. In: Long R, Ellis E, editors. The Canadian tuberculosis standards, 6th ed. Ottawa (ON): Health Canada and the Canadian Lung Association; 2007. p. 274-97.

148. Guidelines for using the QuantiFERON®-TB gold test for detecting Mycobacterium tuberculosis infection, United States. MMWR Morb Mortal Wkly Rep 2005;54(RR-15):49-55

Correspondence to: Dr. Christina Greenaway, SMBD Jewish General Hospital, Division of Infectious Diseases, Rm. G-143, 3755 Cote St. Catherine Rd., Montréal QC H3T 1E2; ca.greenaway@mcgill.ca

\section{Clinical preventive guidelines for newly arrived immigrants and refugees to Canada}

This article is part of a series of guidelines for primary care practitioners who work with immigrants and refugees. The series was developed by the Canadian Collaboration for Immigrant and Refugee Health. 